Communication

\title{
Inoculation of ACC Deaminase-Producing Brevibacterium linens RS16 Enhances Tolerance against Combined UV-B Radiation and Heat Stresses in Rice (Oryza sativa L.)
}

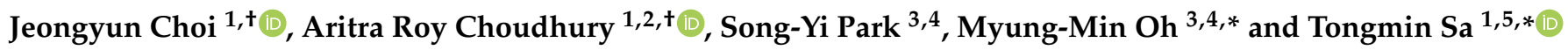 \\ 1 Department of Environmental and Biological Chemistry, Chungbuk National University, \\ Cheongju 28644, Korea; jychoi@chungbuk.ac.kr (J.C.); aritraroy@chungbuk.ac.kr (A.R.C.) \\ 2 Bio-Evaluation Center, Korea Research Institute of Bioscience and Biotechnology, Cheongju 28116, Korea \\ 3 Division of Animal, Horticultural and Food Sciences, Chungbuk National University, Cheongju 28644, Korea; \\ 1songyi1@gmail.com \\ 4 Brain Korea 21, Center for Bio-Health Industry, Chungbuk National University, Cheongju 28644, Korea \\ 5 The Korean Academy of Science and Technology, Seongnam 13630, Korea \\ * Correspondence: moh@cbnu.ac.kr (M.-M.O.); tomsa@chungbuk.ac.kr (T.S.) \\ + These authors have contributed equally to this work.
}

Citation: Choi, J.; Roy Choudhury, A.; Park, S.-Y.; Oh, M.-M.; Sa, T. Inoculation of ACC DeaminaseProducing Brevibacterium linens RS16 Enhances Tolerance against Combined UV-B Radiation and Heat Stresses in Rice (Oryza sativa L.). Sustainability 2021, 13, 10013. https:/ / doi.org/10.3390/su131810013

Academic Editors: R. Z. Sayyed, Noshin Ilyas and Hesham Ali El Enshasy

Received: 15 August 2021

Accepted: 3 September 2021

Published: 7 September 2021

Publisher's Note: MDPI stays neutral with regard to jurisdictional claims in published maps and institutional affiliations.

Copyright: (C) 2021 by the authors. Licensee MDPI, Basel, Switzerland. This article is an open access article distributed under the terms and conditions of the Creative Commons Attribution (CC BY) license (https:// creativecommons.org/licenses/by/ $4.0 /)$.

\begin{abstract}
UV-B radiation and high temperature have detrimental effects on plant physiological and biochemical processes. The use of bacterial inoculants for stress alleviation has been regarded as a sustainable and eco-friendly approach. Hence, this study was conducted to evaluate the ability of 1-aminocyclopropane-1-caboxylate (ACC) deaminase-producing Brevibacterium linens RS16 in enhancing stress tolerance in rice against combined UV-B radiation and heat stresses. A combination of $0.5 \mathrm{Wm}^{-2} \mathrm{UV}-\mathrm{B}$ radiation and $40{ }^{\circ} \mathrm{C}$ of temperature were imposed on rice plants for 5 days. The plants imposed with combined stress had shown significantly higher ethylene emissions compared to the plants grown under normal conditions. In addition, the stress imposition had shown negative effects on the photosynthetic traits, biomass, and genetic material of rice plants. The inoculation of bacteria had shown a $26.5 \%$ and $31.8 \%$ decrease in ethylene emissions at 3 and 4 days of stress imposition compared to the non-inoculated plants. Additionally, bacterial inoculation had also enhanced plant biomass and photosynthetic traits, and had proved to be effective in restricting DNA damage under stress conditions. Taken together, the current study has shown the effective strategy of enhancing stress tolerance against the interactive effects of UV-B radiation and heat stresses by regulation of ethylene emissions through inoculating ACC deaminase-producing bacteria.
\end{abstract}

Keywords: ACC deaminase; Brevibacterium linens RS16; DNA damage; ethylene; heat stress; UV-B radiation

\section{Introduction}

Industrial emissions during the past century have resulted in the depletion of the ozone layer and uncontrolled penetration of UV-B radiation in the Earth's atmosphere [1]. The adaptation of the Montreal Protocol has restricted the widening of the ozone hole [2] and the total recovery of the depleted ozone layer will take decades to revert back to the pre-industrial era $[3,4]$. The exposure to irradiation has shown significant effects on the physiological and biochemical processes of plants, such as a decrease in biomass and leaf area, DNA damage, stress ethylene emission, accumulation of reactive oxygen species and flavonoids, membrane disintegration, and cell death [5-8]. In addition, global warming is another threatening factor affecting the life cycle of plants and has shown negative impacts on the majority of plant physiological characteristics, such as photosynthesis, growth, and water loss due to enhanced transpiration, and pollen viability is also a matter 
of concern [9-11]. The global temperature has already recorded a rise in $0.8^{\circ} \mathrm{C}$ as of 2012 and it is expected to rise up to $1.5^{\circ} \mathrm{C}$, compared to the pre-industrial era, by the end of 21st century [12]. Rice (Oryza sativa L.) is a major crop that is grown in lower latitudinal regions, leading to its exposure towards a higher flux of UV due to the greater solar angle and longer duration of sunlight [13]. Additionally, these regions have also shown a steady increase in the rise of surface temperature in the past decade [14].

Researchers have previously focused on studying the interactive effect of UV-B radiation and heat stress on plants. For example, such combined stresses have shown changes in flavonoid and phenolic profiles in Brassica oleracea var. sabellica and Picea abies [15,16]; altered timelines of bud setting in male and female clones of Populus tremula, leading to decreasing chances of fertilization [17]; shown effects on growth and reproduction in Salix myrsinifolia [18]; and have enhanced volatile organic compound (VOC) emissions from Populus tremula [19]. However, these studies were specific to a few ornamental plants and vegetation native to Europe. Hence, studying the effect of combined UV-B radiation and heat stresses on a major food crop such as rice will be valuable in the field of agriculture.

The use of ACC deaminase-producing, plant growth-promoting bacteria (PGPB) has shown promising results in the enhancement of plant growth and stress alleviation under various environmental conditions [20-22]. However, there have been a lack of studies that explore the effectiveness of bacterial inoculation in enhancing stress tolerance under combined UV-B radiation and heat stresses. Such studies will address the potential strategy to enhance plant growth and productivity in the recent climate change scenario. Brevibacterium linens RS16 is a characteristic ACC deaminase-producing bacteria that has the ability to alleviate a varied range of stresses [21-23] and recently we reported its ability to enhance tolerance against UV-B radiation in rice by regulating ethylene emission levels [7]. Hence, this study was conducted to evaluate the ability of B. linens RS16 in enhancing the stress tolerance of rice against combined UV-B radiation and heat stresses by monitoring ethylene emission, photosynthetic traits, plant biomass, and DNA damage.

\section{Materials and Methods}

Rice (O. sativa L. ssp. japonica cv. Chucheongbyo) seeds were germinated by soaking them on water in a dark chamber at $30{ }^{\circ} \mathrm{C}$ for $72 \mathrm{~h}$. The germinated seedlings were transplanted in a seedling tray and kept in a growth chamber (DS 54 GLP, DASOL Scientific Co., Ltd., Seoul, Korea) with $32{ }^{\circ} \mathrm{C} / 28^{\circ} \mathrm{C}, 16-8 \mathrm{~h}$ day/night conditions, and $70 \%$ relative humidity. The inoculum of $B$. linens RS16 was prepared by growing the bacterium in a nutrient broth until $\mathrm{OD}_{600} \sim 0.8$, washing three times in $0.03 \mathrm{M} \mathrm{MgSO}_{4}$, and eventually resuspending in the same by maintaining $\mathrm{OD}_{600} \sim 0.8$. After 5 days of sowing in the seedling tray, a total of 30 rice seedlings were transplanted in a $60 \mathrm{~mL}$ pot containing $50 \mathrm{~g}$ of nursery soil (Doobaena, Nongkung Co., Jincheon-gun, Korea). The bacterial suspension (10 mL) was inoculated near the root zone of the transplanted seedlings. The non-inoculated plants were treated with $10 \mathrm{~mL} 0.03 \mathrm{M} \mathrm{MgSO}_{4}$. The transplanted seedlings were grown for 2 days in the growth chamber and the subsequent treatments were applied.

UV-B radiation was applied at an intensity of $0.5 \mathrm{~W} \mathrm{~m}^{-2}$ using UV-B lamps (Sankyo Ultraviolet Co. Ltd., Kanagawa, Japan) (the spectral intensity of the fluorescence lamps and UV-B lamps are provided in Figure S1) for $6 \mathrm{~h}$ during the day (9 AM to $3 \mathrm{PM}$ ) and heat stress was applied by raising the temperature to $40{ }^{\circ} \mathrm{C}$ for $2 \mathrm{~h}$ at the 4 th-6th $\mathrm{h}$ (1 PM to $\left.3 \mathrm{PM}\right)$ of UV-B irradiation treatment. Control plants were kept in a different growth chamber and grown without any irradiation or heat stress. Rice seedlings were harvested at 2, 3, 4 , and 5 days after the stress treatment for measuring the ethylene emission, chlorophyll fluorescence, photosynthetic activity, DNA laddering, and phenolic content. Ethylene emission was measured by transferring the pots in a 1-L customized GC bottle and closing the lid for an additional $1 \mathrm{~h}$ in a stress condition, thereby collecting $1 \mathrm{~mL}$ of air from the headspace and injecting it into a gas chromatograph (dsCHROM 6200, Donam Instruments Inc., Korea) equipped with the Poropak-Q column. The photosynthetic rate was measured by using a portable photosynthesis system (LI-6800, Li-Cor, Lincoln, NE, USA) and the 
data were recorded once the rate reached the steady state (in ca. 15-20 min after leaf enclosure). The leaf area was recorded by scanning the leaf enclosed in the measurement block at 300 dpi and analyzing the figure in Image J software. The photosynthetic rate was calculated according to von Caemmerer and Farquhar [24]. Chlorophyll fluorescence was recorded by measuring the ratio of $F_{v}$ and $F_{m}$ using a PAM fluorometer (PAM 2000, Heinz Walz $\mathrm{GmbH}$, Effeltrich, Germany). The rice leaves were adapted to the dark for $20 \mathrm{~min}$ prior to the measurement of chlorophyll fluorescence. The maximum $\left(F_{m}\right)$ and minimum $\left(F_{o}\right)$ fluorescence were recorded using a $20 \mathrm{kHz}$ saturating light pulse with $1100 \mu \mathrm{mol} \mathrm{m}{ }^{-2} \mathrm{~s}^{-1}$ PPFD and the final calculation was done using the formula:

$$
\frac{F_{v}}{F_{m}}=\frac{F_{m}-F_{o}}{F_{m}}
$$

DNA damage due to the combined stress was determined by extracting the genomic DNA from the fresh leaves $(0.5 \mathrm{~g})$ of rice plants using the Wizard ${ }^{\circledR}$ Genomic DNA Isolation Kit (Promega, Madison, WI, USA) as per the manufacturer's protocol and running an electrophoresis using $0.8 \%$ agarose gel. The leaf samples were chosen from the region in which necrosis was the least present for eliminating biasness in the result. The intensity of the genomic DNA band was measured by using a Gel Doc (Biorad, CA, USA). The study was carried out in a randomized block design and the data obtained were subjected to a one-way analysis of variance (ANOVA). The significant differences between the means within the treatments were determined by Tukey's test at $p<0.05$ using SAS package, Version 9.4.

\section{Results and Discussions}

3.1. Bacterial Inoculation Reduced Ethylene Emissions and Enhanced Plant Biomass under Combined UV-B Radiation and Heat Stresses

Elevated levels of ethylene are a typical response for various environmental stress conditions [25]. In this study, ethylene emissions from plants imposed with combined UV-B radiation and heat stresses were significantly higher compared to the plants grown under normal conditions at 2,3, and 4 days after the stress treatment (Figure 1a). These results corroborate the previous studies in which elevated ethylene emissions were induced by UV$B$ radiation in rice plants [7] and heat stress in wheat [26] and soybean [27]. Additionally, the inoculation of $B$. linens RS16 resulted in a significant decrease in ethylene emissions compared to non-inoculated plants at 3 and 4 days after the stress imposition (Figure 1a). The inoculation of bacteria had shown a $26.5 \%$ and $31.8 \%$ decrease in ethylene emissions compared to non-inoculated plants at 3 and 4 days after the stress imposition, respectively. The decrease in ethylene emissions can be attributed to the ability of B. linens RS16 to produce ACC deaminase [23], which can scavenge the precursor of ethylene, ACC, and convert it into $\alpha$-ketobutyrate and ammonia [20,25]. Interestingly, the non-inoculated stressed plants had shown significantly lower ethylene emissions compared to the other treatments. This may be due to the fact that those plants had shown leaf necrosis due to the stress imposition, as shown in Figure S2. Previous studies have shown that these stresses, when imposed individually on plants, can lead to leaf necrosis $[26,28]$, which can be the reason for the accelerated death of leaf tissues of rice and, in turn, the decrease in ethylene emissions during prolonged exposure to combined stresses.

The elevated ethylene emissions have been broadly attributed to the decrease in plant biomass $[20,25,29]$. The combined UV-B radiation and heat stresses have also been observed to decrease plant growth [18]. Similarly, in this study, the combined stress resulted in a significant decrease in the dry weight of rice plants at 2, 3, 4, and 5 days after the stress treatment, irrespective of the bacterial inoculation, compared to the plants grown under normal conditions (Figure 1b). Conversely, the inoculation of B. linens RS16 resulted in a significant increase in the dry weight of the plants compared to the non-inoculated plants under normal and stress conditions at 3, 4, and 5 days after the stress treatment (Figure 1b). The inoculation had shown a $20.3 \%, 19.2 \%$, and $11.9 \%$ increase in the dry weight of rice 
plants compared to the non-inoculated plants under normal conditions at 3, 4, and 5 days after the stress treatment, respectively. In addition, the inoculated plants resulted in a $8.2 \%, 9.4 \%$, and $7 \%$ increase in the plant dry weight compared to the non-inoculated plants under combined stress conditions at 3,4 , and 5 days after the stress imposition, respectively. Such an increase in the plant dry weight can be corroborated with previous studies in which the inoculation of $B$. linens RS16 was able to enhance the dry weight of rice [21] and canola [23] under salt stress conditions. In addition, B. linens RS16 has the ability to secrete hormones such as indole-acetic acid and cytokinins that are important for enhancing plant growth and for the ability to decrease stress ethylene levels through its ACC deaminase activity [23].
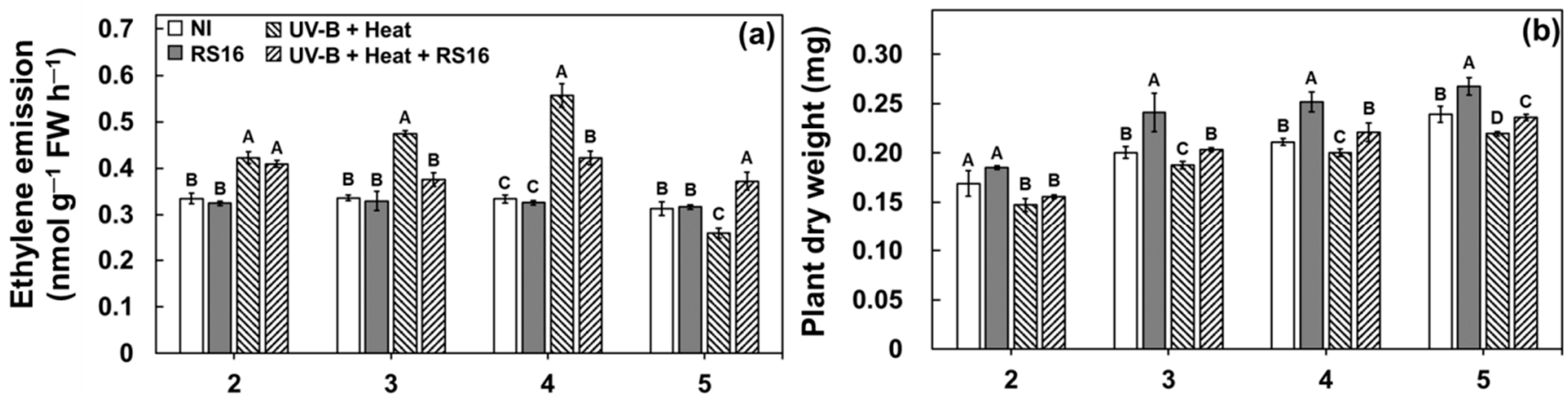

\section{Days after stress imposition}

Figure 1. The effect of $B$. linens RS16 inoculation on ethylene emissions (a) and the dry weight (b) of rice plants imposed with combined UV-B radiation and heat stresses for 2, 3, 4, and 5 days. Different letters indicate significant differences, expressed as $p<0.05$, among the treatments at each day.

\subsection{Bacterial Inoculation Enhances Photosynthetic Traits under Combined UV-B Radiation and Heat Stresses}

UV-B radiation and heat stress have been characterized as major factors in affecting photosynthesis in plants [30,31]. Plants grown under normal conditions have a $F_{v} / F_{m}$ ratio of 0.8-0.83 and environmental stress decreases the ratio below 0.8 [32]. Similar inferences were drawn from the current study, wherein the chlorophyll fluorescence measured in terms of $F_{v} / F_{m}$ were significantly decreased in rice plants imposed with combined UV-B radiation and heat stresses compared to the plants grown under normal conditions at 3,4 , and 5 days after the stress treatment (Figure 2a). These results corroborate with previous studies in which the imposition of UV-B radiation on peas and heat stress on rice had shown a decrease in chlorophyll fluorescence [22,33]. The decrease in chlorophyll fluorescence can be attributed to the severe impact on the functioning of photosystem II under these stress conditions [22,33]. However, the inoculation of ACC deaminaseproducing bacteria had shown a significant increase in chlorophyll fluorescence compared to the non-inoculated plants at 3, 4, and 5 days after the stress treatment (Figure 2a). The bacterial inoculation had shown a $8 \%, 22.9 \%$, and $17.9 \%$ increase in $F_{v} / F_{m}$ measurements compared to the non-inoculated plants at 3, 4 , and 5 days after the stress treatment. A similar effect was observed in the photosynthetic rate of plants imposed with combined stresses (Figure 2b). Additionally, the photosynthetic rate could not be measured from the non-inoculated plants at 4 and 5 days after the stress treatment. This can be due to the enhanced leaf necrosis pertained by the stress conditions that can be observed in Figure S2. The bacterial inoculation had shown a significantly higher photosynthetic rate in rice plants under normal and stress conditions (Figure 2a). The higher assimilation was observed in bacteria-inoculated plants throughout the experimental period for control conditions, whereas the higher assimilation rate was observed for bacteria-inoculated plants at 4 and 5 days after the combined stress treatment in rice plants. The increase in photosynthetic traits by the inoculation of $B$. linens RS16 was observed in rice and eucalyptus under salt and heat 
stress, respectively [21,22]. Although the mechanism of ACC deaminase-producing bacteria regarding the enhancement of photosynthetic parameters still remains unclear, these results can be attributed to previous reports in which the PGPB inoculation assisted in increasing photosynthetic pigments under various environmental stress conditions [34,35]. In addition, the efficiency of ACC deaminase-producing bacteria in enhancing photosynthetic pigment concentrations under stress conditions suggests the ability of bacteria to nullify the adverse effects of combined UV-B radiation and heat stresses by enhancing the activity of electron transporters related to photosynthesis [36].
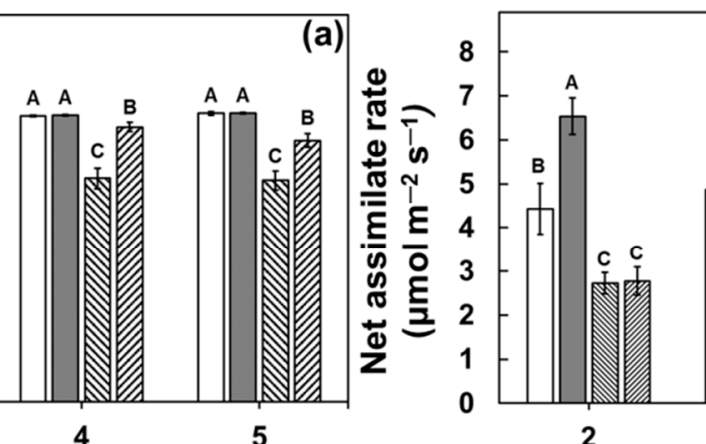

2

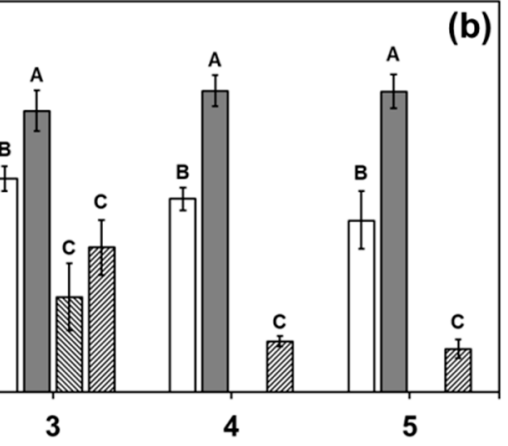

Days after stress imposition

Figure 2. The effect of $B$. linens RS16 inoculation on chlorophyll fluorescence (a) and photosynthetic rate (b) of rice plants imposed with combined UV-B radiation and heat stresses for 2, 3, 4, and 5 days. Different letters indicate significant differences, expressed as $p<0.05$, among the treatments at each day.

\subsection{Combined Stress-Induced DNA Damage Was Alleviated by Bacterial Inoculation}

The induction of DNA damage by UV-B radiation and heat stresses have been characterized previously $[37,38]$. The preliminary idea regarding DNA damage leading to programmed cell death is characterized by studying the effect of environmental stress on the DNA-laddering of the plant [38]. In this study, the DNA-laddering was evident in rice plants imposed with combined UV-B radiation and heat stresses (Figure 3a). In addition, the intensity signal from the genomic DNA loaded on the wells were lower for the stress imposed plants compared to the plants grown under normal conditions (Figure $3 b$ ). Furthermore, the genomic DNA of B. linens RS16 inoculated plants had shown higher intensity signals compared to the non-inoculated plants imposed with combined stresses. As it has been reported earlier, $B$. linens RS16 has the ability to secrete various enzymes such as phytoene desaturase, phytoene synthase, and ectoine synthase that are important for the synthesis of carotenoids, phytoene, and ectoine, which are important for stabilizing the DNA under environmental stress conditions [7]. Conversely, elevated ethylene emissions have been reported previously to accelerate DNA damage in cucumber [39] and the ability of ACC deaminase-producing B. linens RS16 in reducing ethylene emission levels could have minimized the effect of the combined stress on the rice genetic material. 
$\begin{array}{llllll}\text { (a) } & M & \text { M1 } & \text { T2 } & \text { T3 } & \text { T4 }\end{array}$

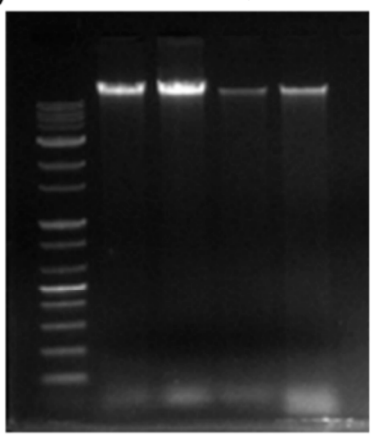

M: DNA Ladder

T1 : NI

T2 : RS16

T3: UV + Heat

T4 : UV+ Heat + RS16

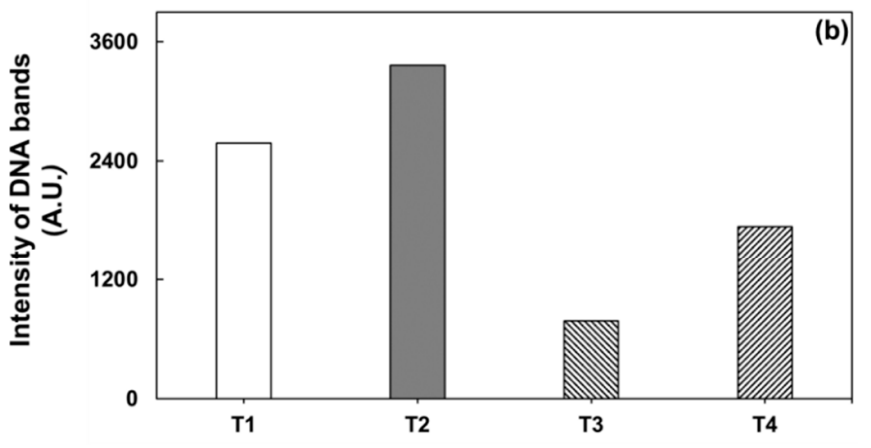

Treatments

Figure 3. DNA-laddering (a) and band intensity (b) of rice genomic DNA inoculated with B. linens RS16 and imposed with combined UV-B radiation and heat stresses for 5 days.

\section{Conclusions}

The combined UV-B radiation and heat stresses have shown severe effects on physiological and biochemical aspects of rice plants. The combined stress treatment has resulted in enhanced ethylene emissions, leading to a decrease in plant biomass and also an acceleration in leaf necrosis during the prolonged exposure period. The combination of ionizing radiation and high temperature have also shown DNA damage that can be attributed to the induction of apoptosis and senescence. The resultant decrease in stress ethylene emissions through the ACC deaminase activity of B. linens RS16 was able to enhance plant biomass. Additionally, the increase in plant biomass can be attributed to the efficient functioning of the photosynthetic machinery through the bacterial inoculation and restriction of DNA damage, leading to the delayed senescence of rice plants. Hence, this study puts forward a novel paradigm in utilizing ACC deaminase-producing bacterial inoculants to enhance the tolerance of rice plants under combined UV-B radiation and heat stresses.

Supplementary Materials: The following are available online at https: / www.mdpi.com/article / 10.3390 /su131810013/s1, Figure S1: Relative spectral distributions of the fluorescent lamps (a) and UV-B lamps (b) of the growth chamber; and Figure S2: Photograph of rice plants imposed with combined UV-B radiation and heat stresses for 3 (a), 4 (b), and 5 (c) days.

Author Contributions: Conceptualization, T.S., M.-M.O., J.C. and A.R.C.; methodology, J.C. and A.R.C.; software, J.C., A.R.C. and S.-Y.P.; validation, J.C., A.R.C. and S.-Y.P.; formal analysis, J.C. and A.R.C.; investigation, J.C. and A.R.C.; resources, T.S. and M.-M.O.; data curation, J.C., A.R.C. and S.-Y.P.; writing—original draft preparation, A.R.C.; writing—review and editing, J.C., S.-Y.P., T.S. and M.-M.O.; visualization, J.C. and A.R.C.; supervision, T.S. and M.-M.O.; project administration, T.S. and M.M.O.; funding acquisition, T.S. and M.-M.O. All authors have read and agreed to the published version of the manuscript.

Funding: This work was supported by Korea Institute of Planning and Evaluation for Technology in Food, Agriculture, Forestry, and Fisheries (IPET) through the Agriculture, Food, and Rural Affairs Convergence Technologies Program for Educating Creative Global Leader, funded by the Ministry of Agriculture, Food, and Rural Affairs (MAFRA) (717001-7).

Institutional Review Board Statement: Not applicable.

Informed Consent Statement: Not applicable.

Data Availability Statement: The data and analyses from the current study are available from the corresponding authors upon reasonable request.

Conflicts of Interest: The authors declare no conflict of interest. 


\section{References}

1. Hideg, É.; Jansen, M.A.; Strid, Å. UV-B exposure, ROS, and stress: Inseparable companions or loosely linked associates? Trends Plant Sci. 2013, 18, 107-115. [CrossRef]

2. Protocol, M. Montreal Protocol on Substances That Deplete the Ozone Layer; Government Printing Office: Washington, DC, USA, 1987; Volume 26, pp. 128-136.

3. Hegglin, M.I.; Shepherd, T.G. Large climate-induced changes in ultraviolet index and stratosphere-to-troposphere ozone flux. Nat. Geosci. 2009, 2, 687-691. [CrossRef]

4. Ballaré, C.L.; Caldwell, M.M.; Flint, S.D.; Robinson, S.A.; Bornman, J.F. Effects of solar ultraviolet radiation on terrestrial ecosystems. Patterns, mechanisms, and interactions with climate change. Photochem. Photobiol. Sci. 2011, 10, 226-241. [CrossRef]

5. Newsham, K.K.; Robinson, S.A. Responses of plants in polar regions to UVB exposure: A meta-analysis. Glob. Chang. Biol. 2009, 15, 2574-2589. [CrossRef]

6. Czégény, G.; Mátai, A.; Hideg, É. UV-B effects on leaves-Oxidative stress and acclimation in controlled environments. Plant Sci. 2016, 248, 57-63. [CrossRef] [PubMed]

7. Choi, J.; Roy Choudhury, A.; Oh, M.M.; Walitang, D.I.; Sa, T. UV-B radiation mediated stress ethylene emission is regulated by ACC deaminase producing bacteria in rice (Oryza sativa L.). Pedosphere 2021. [CrossRef]

8. Surjadinata, B.B.; Jacobo-Velázquez, D.A.; Cisneros-Zevallos, L. Physiological role of reactive oxygen species, ethylene, and jasmonic acid on UV light induced phenolic biosynthesis in wounded carrot tissue. Postharvest Biol. Technol. 2021, 172, 111388. [CrossRef]

9. Ye, C.; Tenorio, F.A.; Argayoso, M.A.; Laza, M.A.; Koh, H.J.; Redoña, E.D.; Jagadish, K.S.V.; Gregorio, G.B. Identifying and confirming quantitative trait loci associated with heat tolerance at flowering stage in different rice populations. BMC Genet. 2015, 16, 41. [CrossRef] [PubMed]

10. Kilasi, N.L.; Singh, J.; Vallejos, C.E.; Ye, C.; Jagadish, S.V.K.; Kusolwa, P.; Rathinasabapathi, B. Heat Stress Tolerance in Rice (Oryza sativa L.): Identification of Quantitative Trait Loci and Candidate Genes for Seedling Growth Under Heat Stress. Front. Plant Sci. 2018, 9, 1578. [CrossRef] [PubMed]

11. Man, Y.; Wang, B.; Wang, J.; Slaný, M.; Yan, H.; Li, P.; El-Naggar, A.; Shaheen, S.M.; Rinklebe, J.; Feng, X. Use of biochar to reduce mercury accumulation in Oryza sativa L: A trial for sustainable management of historically polluted farmlands. Environ. Inter. 2021, 153, 106527. [CrossRef]

12. IPCC. Summary for policymakers. In Climate Change 2013: The Physical Science Basis. Contribution of Working Group I to the Fifth Assessment Report of the Intergovernmental Panel on Climate Change; Stocker, T.F., Qin, D., Plattner, G.-K., Tignor, M.M.B., Boschung, J., Nauels, A., Xia, Y., Bex, V., Midgley, P.M., Eds.; Cambridge University Press: Cambridge, UK, 2013.

13. Kataria, S.; Guruprasad, K. Solar UV-B and UV-A/B exclusion effects on intraspecific variations in crop growth and yield of wheat varieties. Field Crop. Res. 2012, 125, 8-13. [CrossRef]

14. Liu, Y.; Geng, X.; Hao, Z.; Zheng, J. Changes in Climate Extremes in Central Asia under 1.5 and $2{ }^{\circ} \mathrm{C}$ Global Warming and their Impacts on Agricultural Productions. Atmosphere 2020, 11, 1076. [CrossRef]

15. Neugart, S.; Fiol, M.; Schreiner, M.; Rohn, S.; Zrenner, R.; Kroh, L.W.; Krumbein, A. Interaction of moderate UV-B exposure and temperature on the formation of structurally different flavonol glycosides and hydroxycinnamic acid derivatives in kale (Brassica oleracea var. sabellica). J. Agric. Food Chem. 2014, 62, 4054-4062. [CrossRef] [PubMed]

16. Virjamo, V.; Sutinen, S.; Julkunen-Tiitto, R. Combined effect of elevated UVB, elevated temperature and fertilization on growth, needle structure and phytochemistry of young Norway spruce (Picea abies) seed-lings. Glob. Change Biol. 2014, 20, 2252-2260. [CrossRef] [PubMed]

17. Strømme, C.B.; Julkunen-Tiitto, R.; Krishna, U.; Lavola, A.; Olsen, J.E.; Nybakken, L. UV-B and temperature enhancement affect spring and autumn phenology in Populus tremula. Plant Cell Environ. 2015, 38, 867-877. [CrossRef]

18. Randriamanana, T.R.; Nissinen, K.; Moilanen, J.; Nybakken, L.; Julkunen-Tiitto, R. Long-term UV-B and temperature enhancements suggest that females of Salix myrsinifolia plants are more tolerant to UV-B than males. Environ. Exp. Bot. 2015, 109, 296-305. [CrossRef]

19. Maja, M.M.; Kasurinen, A.; Holopainen, T.; Julkunen-Tiitto, R.; Holopainen, J. The effect of warming and enhanced ultraviolet radiation on gender-specific emissions of volatile organic compounds from European aspen. Sci. Total Environ. 2016, 547, 39-47. [CrossRef] [PubMed]

20. Madhaiyan, M.; Poonguzhali, S.; Sa, T. Characterization of 1-aminocyclopropane-1-carboxylate (ACC) deaminase containing Methylobacterium oryzae and interactions with auxins and ACC regulation of ethylene in canola (Brassica campestris). Planta 2007, 226, 867-876. [CrossRef]

21. Chatterjee, P.; Kanagendran, A.; Samaddar, S.; Pazouki, L.; Sa, T.M.; Niinemets, Ü. Inoculation of Brevibacterium linens RS16 in Oryza sativa genotypes enhanced salinity resistance: Impacts on photosynthetic traits and foliar volatile emissions. Sci. Total Environ. 2018, 645, 721-732. [CrossRef]

22. Chatterjee, P.; Kanagendran, A.; Samaddar, S.; Pazouki, L.; Sa, T.M.; Niinemets, Ü. Influence of Brevibacterium linens RS16 on foliage photosynthetic and volatile emission characteristics upon heat stress in Eucalyptus grandis. Sci. Total Environ. 2020, 700, 134453. [CrossRef] 
23. Siddikee, A.; Chauhan, P.S.; Anandham, R.; Han, G.-H.; Sa, T. Isolation, Characterization, and Use for Plant Growth Promotion Under Salt Stress, of ACC Deaminase-Producing Halotolerant Bacteria Derived from Coastal Soil. J. Microbiol. Biotechnol. 2010, 20, 1577-1584. [CrossRef] [PubMed]

24. Von Caemmerer, S.; Farquhar, G.D. Some relationships between the biochemistry of photosynthesis and the gas exchange of leaves. Planta 1981, 153, 376-387. [CrossRef] [PubMed]

25. Glick, B.R. Bacteria with ACC deaminase can promote plant growth and help to feed the world. Microbiol. Res. 2014, 169, 30-39. [CrossRef] [PubMed]

26. Hays, D.B.; Do, J.H.; Mason, R.E.; Morgan, G.; Finlayson, S. Heat stress induced ethylene production in developing wheat grains induces kernel abortion and increased maturation in a susceptible cultivar. Plant Sci. 2007, 172, 1113-1123. [CrossRef]

27. Djanaguiraman, M.; Prasad, P.V.V. Ethylene production under high temperature stress causes premature leaf senescence in soybean. Funct. Plant Biol. 2010, 37, 1071-1084. [CrossRef]

28. Kakani, V.G.; Reddy, K.R.; Zhao, D.; Mohammed, A.R. Effects of ultraviolet-B radiation on cotton (Gossypium hirsutum L.) morphology and anatomy. Ann. Bot. 2003, 91, 817-826. [CrossRef]

29. Chatterjee, P.; Samaddar, S.; Anandham, R.; Kang, Y.; Kim, K.; Selvakumar, G.; Sa, T. Beneficial soil bacterium Pseudomonas frederiksbergensis OS261 augments salt tolerance and promotes red pepper plant growth. Front. Plant Sci. 2017, 8, 705. [CrossRef]

30. Kataria, S.; Jajoo, A.; Guruprasad, K.N. Impact of increasing Ultraviolet-B (UV-B) radiation on photosynthetic processes. J. Photochem. Photobiol. B-Biol. 2014, 137, 55-66. [CrossRef]

31. Song, Y.; Chen, Q.; Ci, D.; Shao, X.; Zhang, D. Effects of high temperature on photosynthesis and related gene expression in poplar. BMC Plant Biol. 2014, 14, 111. [CrossRef]

32. Dobrikova, A.G.; Apostolova, E.L. Damage and protection of the photosynthetic apparatus from UV-B radiation. II. Effect of quercetin at different pH. J. Plant Physiol. 2015, 184, 98-105. [CrossRef]

33. Baker, N.R.; Rosenqvist, E. Applications of chlorophyll fluorescence can improve crop production strategies: An examination of future possibilities. J. Exp. Bot. 2004, 55, 1607-1621. [CrossRef]

34. Khanna, K.; Jamwal, V.L.; Gandhi, S.G.; Ohri, P.; Bhardwaj, R. Metal resistant PGPR lowered Cd uptake and expression of metal transporter genes with improved growth and photosynthetic pigments in Lycopersicon esculentum under metal toxicity. Sci. Rep. 2019, 9, 5855. [CrossRef]

35. Samaddar, S.; Chatterjee, P.; Choudhury, A.R.; Ahmed, S.; Sa, T. Interactions between Pseudomonas spp. and their role in improving the red pepper plant growth under salinity stress. Microbiol. Res. 2019, 219, 66-73. [CrossRef]

36. Pinnola, A.; Staleva-Musto, H.; Capaldi, S.; Ballottari, M.; Bassi, R.; Polívka, T. Electron transfer between carotenoid and chlorophyll contributes to quenching in the LHCSR1 protein from Physcomitrella patens. Biochim. Biophys. Acta (BBA)-Bioenerg. 2016, 1857, 1870-1878. [CrossRef]

37. Du, M.; Zhang, Y.; Chen, H.; Han, R. TaPCNA plays a role in programmed cell death after UV-B exposure in wheat (Triticum aestivum). Funct. Plant Biol. 2021. [CrossRef] [PubMed]

38. Wang, P.; Zhao, L.; Hou, H.; Zhang, H.; Huang, Y.; Li, H.; Gao, F.; Yan, S. Epigenetic Changes are Associated with Programmed Cell Death Induced by Heat Stress in Seedling Leaves of Zea mays. Plant Cell Physiol. 2015, 56, 965-976. [CrossRef] [PubMed]

39. Wang, D.H.; Li, F.; Duan, Q.H.; Han, T.; Xu, Z.H.; Bai, S.N. Ethylene perception is involved in female cu-cumber flower development. Plant J. 2010, 61, 862-872. [CrossRef] [PubMed] 